\title{
HOW DID A MUSIC THERAPY STUDENT WORK WITH PATIENTS WITH DEMENTIA WHO WERE ANXIOUS AND/OR AGITATED?
}

\author{
BY \\ CHIN HSIAU WUNG
}

\begin{abstract}
A thesis
submitted to the Victoria University of Wellington in fulfilment of the requirements for the degree of Master of Music Therapy
\end{abstract}

Victoria University of Wellington 2016 


\section{Abstract}

This research aimed to uncover the strategies and techniques that I used in my work with patients who have dementia and who were anxious and/or agitated. The objective of this study was to examine and learn from my work in order to improve my own, and potentially others' practice. Secondary analysis of data collected from my music therapy clinical practice in a hospital was used as methodology of study. The analysis found 21 techniques and strategies in my work with patients with dementia who were anxious and/or agitated. They include the use of:

(1) Choice; (2) Culture of race (used Maori songs); (3) Direct Engagement; (4) Exploration; (5) Familiar Song; (6) Favourite Songs; (7) Following the Patient; (8) Identity; (9) Imitation and Matching Patients' Sound Making; (10) Improvisation; (11) Lyrics; (12) Matching Tempo; (13) Object-Musical Instrument (drum); (14) Observation; (15) Physical Interaction; (16) Safety; (17) Space; (18) Tempo; (19) Verbal Interaction; (20) Voice Only; and (21) Volume.

These techniques and strategies were developed as I learnt from different articles, books, own experiences as well as supported by my supervisors. Apart from helping patients to reduce their anxiety and/or agitation, maintaining or increasing socialisation, interaction, and general wellbeing of patients seemed important too. Patients are likely to experience less anxiety and/or agitation if their needs are being supported. Findings will be of interest to music therapists and music therapy students working in hospitals or in dementia units in New Zealand. Future research about music therapy work with patients with dementia who are anxious and/or agitated together with their family members is suggested. 
Table of Content

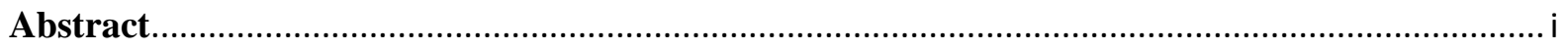

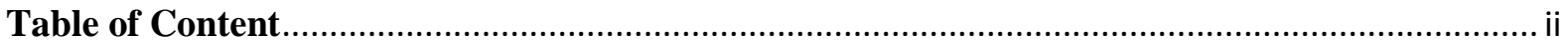

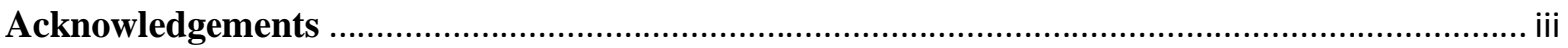

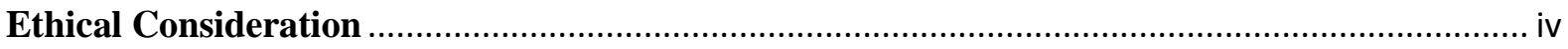

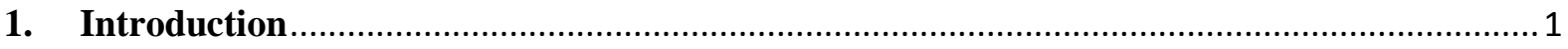

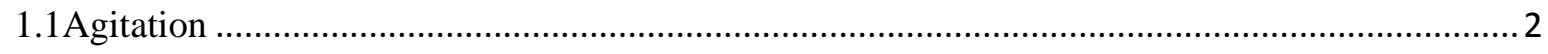

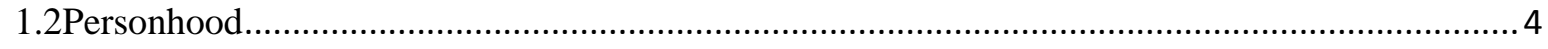

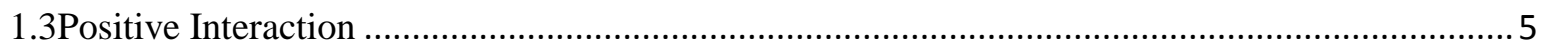

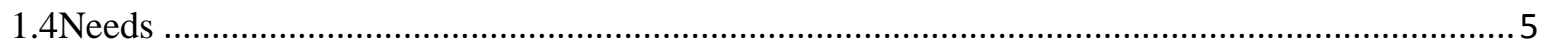

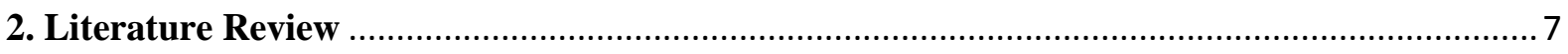

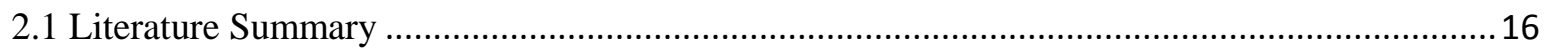

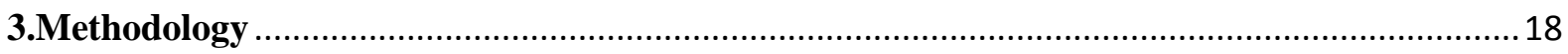

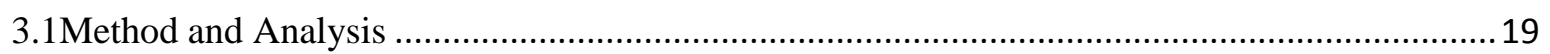

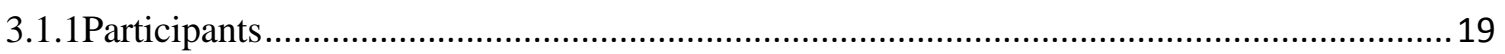

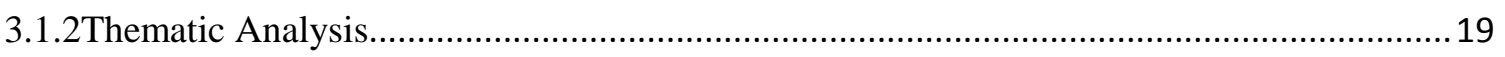

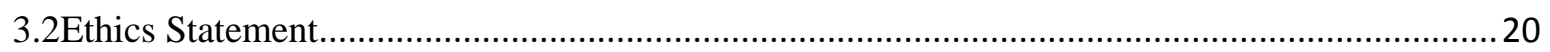

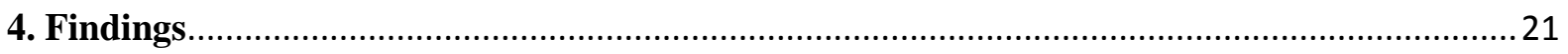

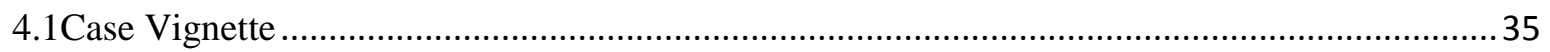

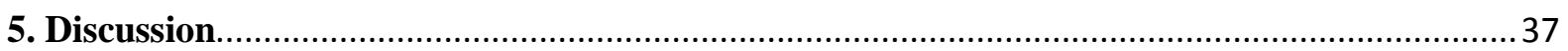

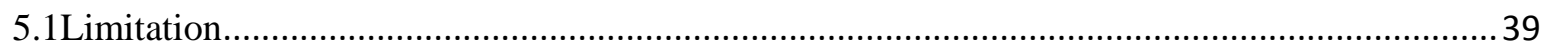

5.2Implication for future Music Therapy research ........................................................................ 40

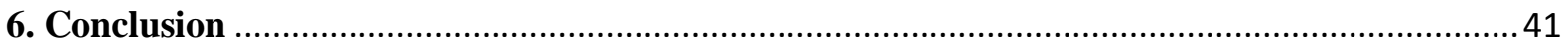

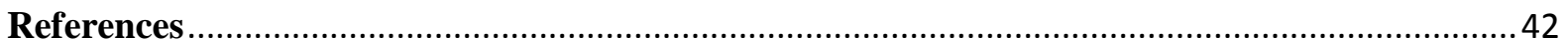

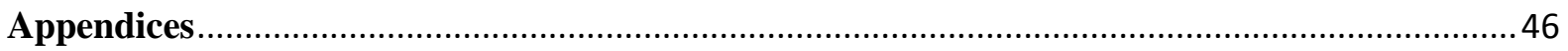

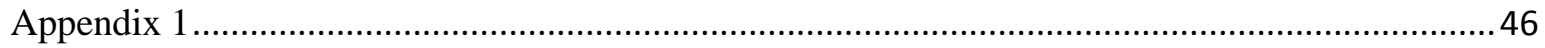

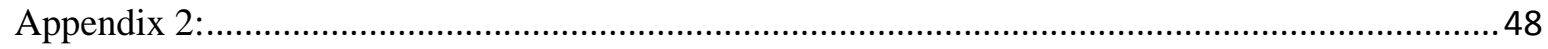

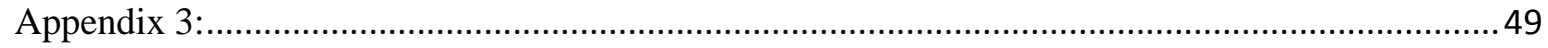




\section{Acknowledgements}

I would like to say thank you to:

Dr Daphne Rickson for your guidance, knowledge, wisdom, help, kindness, and lots of support in writing this exegesis.

Professor Sarah Hoskyns and Dr Daphne Rickson for your teaching, wisdom, understanding, friendliness, generosity, and keep reminding us about being a 'good enough' student and person throughout our studies.

Megan-Berentson Glass for your teaching, supervision, understanding, and help in shaping my work as a student music therapist.

All of the team members in the facility for your help, encouragement, and knowledge during my student placement.

All of the wonderful patients and family members that I met in the facility during my placement.

My friends who have been praying for me during the difficult times and writing of exegesis.

My family members for your unconditional support and care. 


\section{Ethical Consideration}

This project has been reviewed and approved by the New Zealand School of Music Postgraduate committee. The Victoria University of Wellington Human Ethics Committee have given generic approval for music therapy students to conduct studies of this type, reference 0000022131 . The music therapy projects have been judged to be low risk and, consequently, are not separately reviewed by any Human Ethics Committees. 


\section{Introduction}

During my second year of music therapy studies, I worked for eight months as a student music therapist in a hospital in New Zealand. The facility provides care to elderly people with high dependency and with dementia. Nurses, doctors, psychiatrist, occupational therapist, physiotherapist, other health team members as well as caregivers provided care for patients. I worked as a part of the activity team where there was a diversional therapist and two other activity officers who helped in creating different activities in order to help patients in the facility to settle, to enjoy activity, to learn, to have fun, and to maintain a healthy lifestyle. As a student music therapist working in the facility, I could fit in to help patients in managing their illness or disorders by providing music as an expression, creating chances for music sharing, increasing interaction and socialisation, and by supporting individual patient's different needs.

As McDermott, Orrell, and Ridder (2014) point out, music-related interventions such as music listening, choir groups, and music therapy are generally believed to provide support for people who have dementia in terms of their psychological well-being. Even when cognitive function deteriorates, the capability to enjoy and to participate in music can remain unimpaired (Aldridge \& Aldridge, 1992). Hence, even when people experience severe dementia, music may be enjoyed individually or with others as it is easy to be provided and can produce stimulation.

Prior to beginning my placement, I prepared myself by reading articles about music therapy with people who have dementia and found that many of them experience anxiety and/or agitation. So, after I started my placement and worked with some patients in the facility, I became particularly interested in how music therapy might support them to become less anxious and/or agitated. I came out with my topic question: How did a music therapy student work with patients with dementia who were anxious and/or agitated? Then, I also searched to look into what types of behaviours were being described as agitation in elderly people who have dementia. 


\subsection{Agitation}

Agitation is defined as "inappropriate verbal, vocal, or motor activity that is not judged by an outside observer to result directly from the needs or confusion of the agitated individual" (Cohen-Mansfield \& Billig, 1986, as cited in Cohen-Mansfield, 2009, p. 64). It is a term to represent a group of symptoms that may reflect a hidden condition (Cohen-Mansfield \& Billig, 1986, as cited in Cohen-Mansfield, 1991).

Cohen-Mansfield, Marx, \& Rosenthal (1989) identify that:

Agitated behavior is always socially inappropriate, and can be manifested in three ways: (a) It may be abusive or aggressive toward self or others; (b) It may be appropriate behavior performed with inappropriate frequency, such as constantly asking questions; or (c) It may be inappropriate according to social standards for the specific situation, as in putting on too many layers of clothes (p.77).

Agitation or aggressive behaviour is described as a troublesome problem affecting families, caregivers, and elderly people themselves (Sung, Lee, Li \& Watson, 2012). Tan, Wong, and Allen (2005) also found that family caregivers who cared for elderly people with dementia were more distressed compared to professional caregivers. In addition, agitation interferes with the health care supported by professionals and also the wellbeing of the elderly people (Gerdner \& Swanson, 1993; Tabloski, McKinnon-Hwe, \& Remington, 1995). It seems like agitation in elderly people who have dementia is of significant concern to a range of people.

I found an instruction manual of the Cohen-Mansfield Agitation Inventory (CMAI) by Cohen-Mansfield (1991). CMAI is used by caregivers to rate the frequency of 29 agitated behaviours shown by patients (Cohen-Mansfield et al., 1989). As a student music therapist, I learned the 29 agitated behaviours of dementia and these helped me to understand about agitation. They are listed below:

1. Pacing and aimless wandering

2. Inappropriate dressing or disrobing

3. Spitting (including while feeding)

4. Cursing or verbal aggression 
5. Constant unwarranted request for attention or help

6. Repetitive sentences or questions

7. Hitting (including self)

8. Kicking

9. Grabbing onto people or things inappropriately

10. Pushing

11. Throwing things

12. Making strange noises

13. Screaming

14. Biting

15. Scratching

16. Trying to get to a different place

17. Intentional falling

18. Complaining

19. Negativism

20. Eating or drinking inappropriate substances

21. Hurting self or other

22. Handling things inappropriately

23. Hiding things

24. Hoarding things

25. Tearing things or destroying property

26. Performing repetitious mannerisms

27. Making verbal sexual advances

28. Making physical sexual advances or exposing genitals

29. General restlessness

The agitated behaviours are also grouped into four different factors by Cohen-Mansfield (2009): (a) Physically aggressive behaviour; (b) Physically non-aggressive behaviour; (c) Verbally aggressive behaviour; and (d) Verbally non-aggressive behaviours.

Cohen-Mansfield (1996) notes that "agitated behaviors are not obvious outcomes of need...the real reasons for the behaviors may indeed be unmet needs or confusion, but these are not obvious" (p.234). He further explains that agitation does not always appear disturbing 
and at times it could be a strong cue for us. "When nondisruptive, the agitation may be important as a means of understanding the internal state of the person with dementia" (p.234). Various music therapy studies have already employed Cohen-Mansfield's definition of agitation (Gerdner, 2000; Ridder, Stige, Qvale, \& Gold, 2013; Wall \& Duffy, 2010).

\subsection{Personhood}

I also came across Kitwood's book, Dementia Reconsidered which was published in 1997. Kitwood was the founder of Bradford Dementia Group, he emphasised treating people with dementia as persons rather than stressing the disorders that they experienced. Dementia Care Mapping (DCM) is one of the main innovations for the development of person centred care. It is an observational tool to rate the quality of care in dementia nursing settings which was carefully designed to evaluate intervention from the patients' point of view in order to maximise wellbeing. As Clare (2014) mentions, person-centred care focuses on each person as if he or she is special, but not on their disorders. "The prime task of dementia care,...is to maintain personhood in the face of failing of mental powers" (Kitwood, 1997, p. 84). Kitwood also defines personhood as a status being applied by others onto a person in the condition of the person's social being and relationship. The author continues to state that it connotes respect, trust, and recognition.

Kitwood reveals the depersonalisation of people who are suffering from different physical or psychological impairment. He observed that society had generally begun to think of people who have the disorders as 'not real persons'. Few considerations for the causes of dehumanisation included: cultural perspectives of which weak ones were seen as devalued; lack of financial support for potential services; lack of development of proper skills and attitudes for a well emotional care, and defensive reactions resulting from human anxieties and fears that the conditions of dementia might also happen to themselves.

Other studies have also mentioned Kitwood's person-centred approach which involves understanding patients' agitation as a form of communication about their unmet psychosocial needs (Ridder, Stige, Qvale, \& Gold, 2013) and about wellbeing of people with dementia (Harrison, Cooke, Moyle, Shum, \& Murfield, 2010). During an exploratory randomized 
controlled trial by Ridder, Stige, Qvale, and Gold (2013), the researchers mentioned that music therapy intervention was not about reducing agitation. Rather, "a decrease in agitation can be explained as a measurable 'side effect' of having psychosocial needs met" (p.670). Other published studies also mentioned about Kitwood's (1997) 'positive person work' and 'personhood' (Dassa \& Amir, 2014; McDermott, Orrell, \& M. Ridder, 2014; Ridder, Stige, Qvale, \& Gold, 2013; Wall \& Duffy, 2010).

\subsection{Positive Interaction}

Kitwood says that dementia is a loss of intellectual ability, and a loss of a routine way of life. It can be seen as a mourning process. He claims that the interpersonal skills of a patient who has dementia is determined by how much the person is allowed to maintain unimpaired relationships, to enjoy and learn, and to make use of his or her skills. Good interactions are involved in a good dementia care. The positive interactions work well with person-centred care. For example: fostering skills, maintaining emotional health, or helping to cope with mental illness. Kitwood then refers to twelve types of positive interaction as: Recognition, Negotiation, Collaboration, Play, Timalation, Celebration, Relaxation, Validation, Holding, Facilitation, or Creation and Giving. Kitwood further articulates that interaction between two persons means to understand and to respond to each other rather than just replying to signals. It implies expectation, reflection, creativity, and anticipation. "Interaction occurs as each interprets the meaning of the others' actions" (Kitwood, 1997, p.15).

\subsection{Needs}

Kitwood comes out with five needs of people with dementia, which all came into a centre point of need for love: comfort, attachment, inclusion, occupation, and identity. "The needs are more obvious in people with dementia, who are far more vulnerable and usually less able to take the initiatives that would lead to their needs being met" (Kitwood, 1997, p.81). He explained that all of the five needs are not necessary in every human being but will basically function as part of basic needs. The five needs would extend over to each parts and the achieving of one need might lead to achieving of another needs too.

In Kitwood (1997), Gearing wrote: 
What Tom Kitwood has offered is a way of approaching the work which is at one and the same time practical and based on the view of the sufferer as a whole person. His work has broken the negative link in dementia care between 'no cure' and 'no hope', by showing how help can be given and by offering a vision of a new culture of care... His approach acknowledges the unique subjectivity of the person with dementia (their unique way of experiencing life and relationships); seeks to validate that experience and the reality of their feelings; and, unlike the old paradigm of dementia care (which regarded the behaviour of the person with dementia as meaningless), tries to uncover the meaning of behaviour which may seem irrational and problematic (vii-viii). 


\section{Literature Review}

World Health Organization (2012) describes Dementia as a syndrome:

Usually of a chronic or progressive nature - in which there is deterioration in cognitive function (i.e. the ability to process thought) beyond what might be expect from normal ageing. It affects memory, thinking, orientation, comprehension, calculation, learning capacity, language, and judgement. Consciousness is not affected. The impairment in cognitive function is commonly accompanied, and occasionally preceded, by deterioration in emotional control, social behaviour, or motivation (n.p.).

People who have dementia usually develop challenging behaviour as the disorder progresses, because their cognitive impairment leaves them unable to manage the difficulties they are experiencing. Gold (2014) notes that people who have severe dementia communicate their bad experiences to the others by showing challenging behaviour. The author further claims that music therapy could help patients in terms of their psychological, behavioural, and social functioning as well as act as a creative intervention itself. By using words and musicmaking, trained therapists could help and improve patients' social behaviour, emotional, or motivation such as their sense of self, their expression of feelings, and their capability to communicate and to relate to other people (Gold, 2014).

Elderly people who have dementia also often experience anxiousness, disorientation, social isolation, changes of mood, and agitation. Sole, Mercadal-Brotons, Galati, \& Castro (2014) mention that the emotional welfare of people with severe cognitive impairment is poorer than people with less cognitive problem. Also, Blackburn \& Bradshaw (2014) state that the majority of people with dementia have limited ability to communicate or to use words. With the loss of ability to speak and to use languages, feelings of isolation can be enduring (Craig, 2014). However, Craig further claims that "music therapy can reduce anxiety and stress, and 
enhance emotional wellbeing, through verbal and non-verbal expression, increased social interaction and cognitive stimulation" (p.12).

People with late stage of dementia might not be able to join in community group singing as they may show challenging behaviour and may not be able to communicate due to cognitive impairment (Gold, 2014). Gold further points out that their demonstration of limited engagement, movement, concentration, and disturbed behaviour may make it hard for them to be included in groups as their agitation or distress might negatively influence the others (Gold). Hence, Gold conducted a weekly music therapy group for nine patients with late stage dementia, 45 to 60 minutes each during a four- month period, and found out that eight of the nine patients had shown consistent improvement in their moods or behaviours scores, except one who showed frustration subsequently on music therapy day.

Sung, Lee, Li, and Watson (2012) also conducted an experimental study on elderly people who have dementia with behavioural and psychological symptoms and the study resulted that group music intervention reduced their anxiety scores significantly, although the difference of agitation scores were not significant. In addition, Sung et al. also suggest that elderly people who have dementia can interact socially or communicate with each other during group music. These findings contradict Gold's (2014) findings that people with late stage of dementia might not be able to join in community group singing.

Similarly, Ridder, Stige, Qvale, \& Gold (2013) mentions that people who have dementia experience memory impairment, and deficits in attention, social skills, and understanding. However, engagement in music interactions seemed to relieve the difficulties and could help in reducing agitation. Clare (2014) says that music therapy aims to preserve a person's skills and abilities and to improve quality of life as well as helping to reduce behavioural problems. Music therapy can help to ameliorate emotional and social needs, promote safe and engaging surroundings, and to reduce problem behaviour of people with dementia (Cohen-Mansfield, 2005, as cited in Chang, Huang, Lin, and Lin, 2010). Besides, a reduction in disruptive behaviours during music or during social interaction of patients with dementia has also been noticed (Cohen-Mansfield, 2005, as cited in Clare, 2014). 
Hence, music therapy is widely being used with elderly people with dementia in all aged care settings for different advantages including coping with their behavioural problems such as agitation and/or anxiety.

Several studies show the effect of individualised passive listening to lessen the agitation or behaviour problem of elderly people. Gerdner and Swanson (1993) implemented individualised passive music listening for five elderly patients from a health centre who were confused and agitated. Patients' agitated behaviours were observed and recorded for two weeks from 3:30p.m. to 5:00p.m. During the second week, individualised music was played on audio cassette player from 3:30p.m. to 4:00p.m. Patients' mean number of agitated behaviours from 3:30pm to 4:00pm were compared between week one and week two. Mean numbers of agitated behaviours post intervention from 4:00pm to 5:0pm were also compared between week one and week two. Results showed that in patient one's life, the number of agitated behaviours decreased during and post intervention and the number during post intervention was smaller than the baseline equivalent time period. Patients two, four, and five also showed a reduction of agitated behaviours during music intervention and slightly less again during post intervention. However, for patient three, whom the importance of music in her life was unidentified, did not show a noticeable decrease of agitated behaviours. The findings suggest that individualised passive music listening could be one of the approaches to help elderly patients who demonstrate confusion and agitation.

Individualised music listening seems to be more effective for elderly people who experience agitation. Gerdner (2000) conducted a study to examine the effects of individualised passive music listening versus classical relaxation passive music listening on the agitation of elderly people with Alzheimer's disease and related disorders (ADRD). Thirty-nine elderly people from six participating long-term-care facilities were included in the study. The subjects met the criteria for agitation, having mild to severe cognitive impairment, and were aged between 70 and 99. Subjects were divided into two groups of Group A and Group B. Group A received individualised music listening for 30 minutes, twice per week for a duration of six weeks. After that, they received another two weeks of no music before another six weeks of classical relaxation music listening. Group B received music listening in the same procedure but started with classical relaxation music listening first. Music was played in subjects' 
familiar places in the facilities. The least square means of frequency of agitation during baseline, classical music, and individualised music were recorded. First 30 minutes of the music played and the equivalent baseline assessment and 30 minutes after the music played and the equivalent baseline assessment were then compared. The results showed that individualised passive music listening reduced agitated behaviours of subjects significantly during and following the intervention compared to classical relaxation music.

However, using only calming classical music listening does have its effect too. Tabloski, McKinnon-Hwe and Remington (1995) conducted a quasi-experimental study to find out the effects of calming music and passive listening on the level of agitation in nursing home residents experiencing cognitive deficits. Twenty patients who had dementia were selected and each exposed to 15 minutes of calming recorded music in their rooms or familiar places. Slow tempo classical music was used. Agitated Behavior Scale (ABS) was used to assess the level of agitation for 15 minutes before, 15 minutes during, and 15 minutes after listening to music. It was repeated again the following week to reflect the scores differences. Results showed that calming passive music listening reduced the level of agitation in the patients especially during and after the treatment. When music treatment terminated, the level of agitation increased, but not to the same level as before treatment.

In addition, there was another quasi-experimental design conducted by Chang et al. (2010) to examine the effect of nature background music during lunch hour on the behaviour problem of forty one elderly people with dementia in Taiwan. Music such as bird song, running water, or music from single piano was selected. The duration of the study took a period of eight weeks to complete. Music was broadcasted on week two and alternate weeks from $11 \mathrm{am}$ to $12 \mathrm{pm}$ while no music was played on the remaining weeks. Data was collected for all eight weeks period of time. The Chinese version of CMAI was used to record the frequency of problem behaviour. Results showed significant reductions in verbally aggressive behaviour and physically aggressive behaviour. The authors concluded that the background music programme helped decrease problem behaviours in elderly people who have dementia. 
Group music sessions also seem to be very useful for patients with dementia. Ueda, Suzukamo, Sato, and Izumi (2013) conducted a systematic review and meta-analysis on 20 articles with randomized controlled trials (RCTs), controlled clinical trials (CCTs), and controlled trials (CTs) to examine the effects of group music therapy (live music therapy, passive music listening, and rhythmic exercising during music) on behavioural and psychological symptoms of dementia (BPSD), activities of daily living (ADL), and cognitive function of patients with dementia. Mostly, preferred or familiar music was used. Live group music therapy sessions were conducted by music therapists, but passive group music listening sessions were conducted by nurses, and some group music listening incorporating rhythm movements and exercises were conducted by other therapists. Results showed that group music therapy had moderate effects on anxiety, small effects on depression and behaviour, but there was lack of evidence to show the effects of music therapy on ADL and cognitive function. It seemed that it would be necessary to have an intervention period of more than three months. Lastly, the study concluded that music therapy can be effective in reducing BPSD in patients with dementia and recommended music therapy as part of the management for BPSD.

Furthermore, Craig (2014) conducted a systematic review on eight articles to examine the efficiency of live group music therapy on people with dementia who have agitation. The review concluded that 30-50 minutes of live group music therapy offered two to three times per week can to reduce agitation in people with dementia. They suggested the music therapy should be conducted by professional music therapists to successfully achieve the effects. The use of familiar or individualised music was shown to be important too.

An experimental study conducted by I et al. (2011) investigated the effectiveness of live group music interventions on agitated behaviour of elderly people with dementia in Taiwan. One hundred patients took part and completed the study. Forty-nine patients were divided into experimental group while 51 patients were in the control group. Before sessions, patients' favourite music was collected through interviews so music interventions were tailored appropriately. The experimental group received 30-minutes live group music interventions, twice a week, for a total of six weeks while the patients in the control group continued with their everyday daily activities. Type of daily activities was not mentioned. 
Assessments of agitated behaviours in both of the groups were conducted before the intervention, and at the sixth and twelfth group music sessions, and one month after the intervention, using Chinese version of the Cohen-Mansfield Agitation Inventory (C-CMAI). The results showed that there were significant decreases in the agitated behaviour scores in the experimental group at sixth session, twelfth session, and one month after the intervention. Hence, live group music intervention has proved to reduce the agitation behaviours in patients with dementia.

However, when recreational activities were to compare with live group music therapy, both showed similar effectiveness in reducing agitation. In a randomised controlled design conducted by Vink, Zuidersma, Boersma, Jonge, Zuidema, and Slaets (2013) to compare the effect of live group music therapy and the effect of general recreational activities on reducing agitation in elderly people, music therapy showed no greater benefits for reducing agitation than the general activities. Forty-three residents were in the music therapy group while 34 residents were in the recreational activities. Recreational activities included playing shuffled board, cooking, handwork, and puzzle games. Both group activities were offered for forty minutes, twice per week in a total of four months period. A modified Cohen-Mansfield Agitation Inventory (CMAI) was used as an assessment tool for the agitated behaviours in elderly people. The active control group intervention and music therapy group intervention had shown to be equally effective in reducing agitation in elderly people who have dementia.

Contrastingly, another randomised controlled trial conducted by Cooke, Moyle, Shum, Harrison, and Murfield (2010) to investigate the effect of live group music programme on patients with dementia had shown no effects in reducing agitation and anxiety. Forty-seven participants from two aged care facilities participated in a randomised cross-over design of live group music intervention and reading control group. Two musicians led the song singing and active listening in the group music sessions while a trained facilitator took charge in the group reading control sessions. For group music, 30 minutes of familiar songs singing accompanied by guitar playing and 10 minutes of active listening from recorded instrumental music were facilitated. Both familiar songs singing and instrumental recorded music were used so that everyone could have a rest from singing while patients who liked instrumental music could enjoy too. The two musicians encouraged participants to be actively involved 
during sessions. In the reading group control, social activities such as telling jokes and quiz activities were facilitated alongside reading, to match and compare with the group music sessions.

Each group activities were conducted for 40 minutes, three times a week, for a duration of eight weeks. A washout period of five weeks followed. Participants were then crossed over into the opposite group activities, and another eight weeks period of the procedure were repeated. Analysis revealed that in both music and reading control groups, verbal aggression increased and no significant effect of music reducing agitation and anxiety was found. It indicated that live group music did not show any significant effects on agitation and anxiety.

In addition, in a non-randomised experimental design conducted by Ledger and Baker (2007) to examine the long-term effects of group music therapy on the agitation levels of people who have Alzheimer's Disease, results indicated that there were no significant differences in the frequency, range, and severity of agitation between the experimental group and control group over the one year period. Twenty-six patients participated in the weekly live group music therapy for about 30 to 45 minutes each while 19 patients participated in the control group, receiving only standard nursing and therapy care. The study however suggested that music therapy is useful in reducing agitated behaviours as an immediate effects for people who have Alzheimer's disease.

Next, Cox, Nowak and Buettner (2011) used one-to-one live violin music performance in a quasi-experimental design study and found out that live music reduced agitated behaviours among seven people who had Alzheimer's disease. Participants received three sessions of one-to-one music. Popular and familiar music was played. Each session consisted of 15 minutes observation period, 18 minutes musical intervention and another 15 minutes postintervention observation period. A modified CMAI tool was used to rate the frequency of agitated behaviours. Results suggested that live music on one-to one basis reduced agitated behaviour among participants with Alzheimer's disease. However, the limitations of this study were the small numbers of participants involved and the measurement tool developed and used for this study was not validated. 
There was also one descriptive case study by Fitzgerald-Cloutier (1993) which investigated the effectiveness of music therapy and reading to reduce wandering for a resident, Claire, an eighty-one-year-old female diagnosed with probable Alzheimer's disease who resided in a nursing home. After daily observations, music therapist found out that the time between 3:30pm and 4:30pm seemed to be one of Claire's most agitated periods. Baseline data recording the length of time Claire wandered within this hour was undertaken for four days. Then, music therapy sessions started at about the same time. After twenty consecutive music therapy sessions (except weekends and when Claire was resting during the time no music therapy session was given), one week of no intervention was given before another twenty sessions of reading followed. In the music therapy sessions, the music therapist sang with Claire in acapella while in the reading sessions, the music therapist read articles from books and magazines to Claire. The therapist chose reading because it uses human voices in a particular rhythmic pattern quite similar to the acapella singing except without any other stimulus.

Results showed that the total amount of time Claire remained seated in music therapy sessions was 214.25 minutes while the total amount of time Claire remained seated during reading sessions was 99.07 minutes. The length of time Claire sat during music therapy sessions increased gradually for most of the sessions while the length of time Claire sat during reading sessions was irregular. This study showed that music therapy could be one of the interventions to help patients who have dementia in later stages. Claire's engagement in music was important. Also, the continuation of music therapy sessions after reading sessions ended would be useful to prove that cognitive decline was not one of factors for Claire's longer amount of sitting time during music therapy.

Ridder, Stige, Qvale, and Gold (2013) conducted a crossover, exploratory randomized controlled study to investigate the effects of individualised music on agitation, medication, and quality of life of 42 participants with dementia. Participants were first grouped randomly into either control group or music therapy group and interventions started on week 1 to week 6. Then, the groups swapped and continued on week 8 to week 13. Data collection took place on week 0, week 7, and week 14 using CMAI and quality of life (Alzheimer's Disease- 
Related Quality of life (ADRQL)). Prescription of medication was registered on Week 0 and all changes of prescription reported and reviewed on Week 14.

Individual music therapy sessions were conducted by music therapists twice per week for six weeks while standard care was received by each participant from the control group. In music sessions, the therapists practiced Kitwood's (1997) 'personhood' and 'positive person work' philosophy when facilitating singing, improvising, dancing, listening, talking, and other musical interactions as a person-centred approach. The results showed that agitation and disruptiveness scores during music therapy were greatly reduced compared to the control group. In addition, medication increased for some participants in the control group but not in music therapy group. This study also suggested a larger sample would be necessary to investigate the relationship between numbers of agitated behaviours of patients and their quality of life. 


\subsection{Literature Summary}

Different music interventions or music therapy related studies to investigate the effectiveness of music or music therapy in managing agitation, anxiety or behaviour problem in elderly people who have dementia were discussed. Passive individualised music listening seemed helpful for patients who had confusion or agitation because patients were able to access to music even in their late stage of dementia (Aldridge \& Aldridge, 1992). In addition, listening to individualised music was probably better than other music selections if they were to compare with each other. Calming music and background music listening seemed helpful in reducing agitated behaviours too.

Live group music therapy would potentially reduce anxiousness after a long period of intervention of more than three months. The reasons could be patients enjoyed being in a group with other people or enjoyed singing and listening to familiar music together. So, they became less anxious. Familiar or individualised music seemed an important musical choice to always be considered for reducing anxious and agitation. Besides, it is also important to have music therapy sessions conducted by music therapists to ensure optimum effects were achieved (Craig, 2014).

Next, live and one-to-one music seemed helpful and easy to encourage interaction from people who have dementia. When more engagement occurred, patients seemed to have reduced agitation. When patients became alert after listening to music and sound, they might exhibit less agitation too. Last but not least, it seemed to be a promising approach when Kitwood's (1997) 'personhood' and 'positive person work' was considered along with music therapy interventions. Patients could feel the warm interaction and might feel respected through positive-musical-interaction. So, they would have lesser agitated behaviours.

So, it seems like music therapy can help people who have dementia to lessen their agitation and anxiety as well as to improve their quality of life although some studies had shown no impact or significant effects. Different music therapy or music interventions were described in mentioned studies. However, I have not come across articles which describe in detail the 
strategies and techniques being used when interacting with patients with dementia who were anxious and/or agitated. This study will contribute to that literature. 


\section{Methodology}

Constructivism relies on researchers' own views or ideas to give meaning to a certain object. Researchers' experiences, histories, cultures, societies, and interactions with others guide the different explanations or meanings to an object. In other words, researchers search and construct meanings for certain experiences influenced by their own life stories or engagement with others socially. There are no certain theories or formulas but researchers came out with their own understanding after they gain experiences from interacting with people around, or from their own cultural norms. Researchers will have to 'position themselves' in the research to find a way to acknowledge how their ideas and thinking came from different aspects, as often researchers' interpretation was from their own background (Creswell, 2007). "The researcher's intent, then, is to make sense (or interpret) the meanings others have about the world" (p.21).

Schwandt (2001) highlights that "we do not construct our interpretations in isolation but against a backdrop of shared understandings, practices, language, and so forth" (p.30). He further says that qualitative in research could mean to "understand the meaning of human action" (p.213). As Creswell (2007) states, qualitative research reflects an interpretation of data considering the researchers' social, political, and cultural context, the readers of a study, and the participants.

My study is based on qualitative secondary analysis of data, which is a methodology for doing research using pre-existing data to answer new questions (Heaton, 2004). According to Smith (2008), qualitative secondary data could involve second hand data from written information, interviews, conversations, pictures, or ethnographic reports. Smith further says that secondary analysis is important in teaching students about research methods. It is also helpful in teaching statistics as students can use the real data such as survey questionnaires to look into patterns and findings, so to relate to their own learning. 
In this study, I looked back at my own clinical notes and reflection notes collected when I worked in the facility, to look for answers to my research question: "How did a music therapy student work with patients with dementia who were anxious and /or agitated?"

\subsection{Method and Analysis}

\subsubsection{Participants}

I included 10 patients in my study to look for answers to my topic question. Four of them were male and six of them were female. They were patients who had dementia or Alzheimer's disease who were agitated and/or anxious.

Some of the patients experienced more than one distinct medical condition (comorbidity) (Valderas, Starfield, Sibbald, Salisbury, \& Roland, 2009). However, I chose to include these patients in my study as their data was also related to solving my topic question.

\subsubsection{Thematic Analysis}

Data included clinical notes and reflective journals that I collected throughout the period of my student placement in the facility. I excluded some clinical notes which were not related to the question. After that, I started data analysis using thematic analysis. According to Braun and Clarke (2006), thematic analysis is "a method for identifying, analysing, and reporting patterns (themes) within data" (p.79). They also mention that a theme can help to derive crucial information from the data which is related to research question. Besides, it gives some meaning or patterned response from the data set. They also explain that thematic analysis allows researchers to determine the themes in many different ways. "Analysis involves a constant moving back and forward between the entire data set... and the analysis of the data that you are producing" (p.86). Lastly, they provided six steps of analysis as a basic guide to thematic analysis: (a) familiarising yourself with the data; (b) generating initial codes; (c) searching for themes; (d) reviewing themes; (e) defining and naming themes; and (f) producing the report. (See Appendix 3 for analysis process) 


\subsection{Ethics Statement}

As I am using qualitative secondary of analysis of my own data that I collected from my music therapy student placement, there are no direct participants in this study. However, I have included a Case Vignette in the study where I illustrate my personal interaction and musical experience with a patient during music therapy. Some information regarding the patient was included. Informed consent has been gained from the patient's family member to allow me to use the patient's data in this study. I also protected the anonymity of the patient by using non-de-plumes in this study.

I abided by the Code of Ethics for the Practice of Music Therapy in New Zealand (Music Therapy New Zealand, 2012) and the code of ethical conduct of research teaching and evaluations involving human participants (Victoria University Human Ethics Committee approval \#22131. Approval date $15^{\text {th }}$ of July 2015). The music therapy programme leaders at Te Koki New Zealand School of Music have gained ethical approval for Master of Music Therapy students wishing to engage in observational studies, theoretical or case study research. Master of Music Therapy ethical template for student research in NZSM 526 undertaken as observational studies, theoretical or case study research). Secondary analysis of data obtained from usual clinical work falls into the category of observational studies (i.e. there is no deviation from usual practice). 


\section{Findings}

I found 21 techniques and strategies that I used while working with patients with dementia who were anxious and/or agitated. Some of the techniques and strategies I used during my music therapy work were influenced by different articles, books, and work experiences that I learned from.

\section{1)Choice}

I gave choice to patients when we were singing songs together because it enabled them to take control and to be in control. When I gave them two contrasting songs to choose from when we sang together, or gave two different choices to choose from during a simple lyric substitution, I noticed that patients often seemed to feel a sense of competence. That happened when they were responding to me and were clearly making the choice in their own ways.

In addition, I felt that there were more positive interactions from residents when I provided them choices to choose from. I think that it helped to shape a structured way for them to respond to me which would allow them to feel less confused. When patients were feeling able to take control during sessions, there was an increase in our interaction that gave opportunities to further support their needs.

16/6/2015: I gave choices between You Are My Sunshine and Te Aroha, and I noticed that she might like You Are My Sunshine as she gave more 'sound'. When I started singing, she tapped on the drum in faster tempo, so, I also sang faster.

\section{2) Culture of race (used Maori songs)}

I used songs from patients' culture because it seemed important to be able to connect to their own culture. I think it might help patients to restore some knowledge of cultural elements they inherited by singing or by listening to Maori songs. It could help them to feel a sense of self too. I used Maori songs to connect to patients during sessions, to encourage more participation or expression, and as a method to engage patients back into sessions.

It seemed that by using Maori songs, positive responses occurred and it helped to enhance our connections during sessions. Patients would respond briefly both verbally and musically. 
When the therapeutic relationship was developed, it might meet part of patients' social needs and might reduce their agitated behaviours. Furthermore, if a particular song has a significant meaning for a patient, it might help him or her to feel calm and relaxed too.

When I sang Maori songs with patients, I did not have a wide repertoire but I learnt a small number during my studies. I had to make inquiries with patients' family members when I met them during their visits. Although I often found that the family members were not able to suggest Maori songs upon request, they would always recognise some songs that I mentioned or sang to them, and gave positive feedback about the songs. I then felt relieved when I used the songs with patients.

21/7/2015: stood up, go to window, closed the window, I included her back by asking her to sing us a Maori song. She came back, stopped opening and closing window which was out of my expectation, and sat down. She smiled after I requested again.

\section{3) Direct Engagement}

I always engaged directly with patients. For example, I met them face to face, greeted them with a smile, stood and sang in front of them while giving eye contact, and worked physically close to them without invading their space. I think it sent them a message that I was interacting with them or was socialising with them. When I engaged with them directly, it they were able to focus on me directly and it seemed to distract them from other thoughts.

Even though responses were sometimes minimal and inconsistent, when I interacted with patients directly both verbally or musically, I believed that it created an opportunity for them to maintain their ability to interact or socialise with people. Patients sometimes seemed to recognise and acknowledge my interaction by responding to me with smiles, eye contact, brief verbal, facial expression, and other interactions depending on their individual communication styles.

I think it was important to understand and to feel sympathy towards patients with dementia in my work and engaging directly with them helped that. The reason was patients who were experiencing difficult times or difficult feelings at the moment might indirectly affect me too when I was interacting with them. However, I believed that close interaction and direct engagement with patients would sometimes produce a feeling of comfort and a feeling of closeness that seemed important to patients with dementia. 

!" He looked at me and said "hello! You come again!" so I said: "Yeah! I come again!" I asked whether can we sing some songs together and then started singing while following him.

4) Exploration

I had to explore on patients' reactions when I needed to find different techniques and strategies to work better with patients. It is important to know that when I explored, I already had regular music therapy sessions with them and I felt that I had basic understanding of their usual behaviours and their different communication ways, so I could try my best to avoid upsetting them with the different approaches.

Some of the examples when I explored on patients' responses during my work were: I offered and shared a song with patients instead of giving direct responses when they were focusing on negative situations; I persisted and offered to sing a song even when patients rejected me seemingly without a second thought; I created different sounds by knocking repetitive rhythms on table and wondered if patients would continue showing more musical responses with me, although they might feel agitated; and I challenged patients to verbally response to me or expected patients to have more interaction with me.

Although some of the methods did not seem to be working, I did learn some important approaches that would help my work with the patients. I found important elements that would better support patients and also received different responses that were not expected. I also felt that I could understand and support them better. Besides, I also noticed some approaches that might not be effective. It was important to me so that I could always improve my work when interacting with patients. These trials and errors were very important.

10/7/2015: I knocked on the table with some rhythms, observed him, and repeated the rhythms again. Soon, he wanted to push the table, so I stopped knocking and played guitar and sang Puff the Magic Dragon. Luckily, he seemed distracted with the song and stopped pushing and seemed listening to song. He appeared calm, and left the table.

\section{5) Familiar Songs}

I used familiar songs with patients because familiar songs could produce reassuring effect. Patients often felt less anxious or agitated, and had positive mood change when singing or listening to their familiar songs. Some familiar songs were composed in simple musical 
structures so I was able to change some of the lyrics while still allowing patients to follow and to sing along easily. It could lead to more enjoyment during singing. Singing familiar songs seemed to be a good way to express ideas and feelings. Furthermore, some patients seemed to feel calm by just listening too.

I sang familiar songs with patients to create meaningful moments together when they wandered around aimlessly. It could also sometimes help them to reduce wandering and other agitated behaviours. I also used a simple song from their childhood era with a patient because the song was simple and was easily accessed by the patient. The childhood song could help to reduce anxiousness or wandering when the patient was engaging in it.

It seemed like familiar songs could also help in increasing interaction. Patients might feel comfortable and relaxed so further verbal interaction, physical gestures, eye contact, smiles, singing, and other interactions occurred. When verbal interaction was limited, patients responded with voice or sound making as a form of interaction. Maintaining interaction or providing opportunities to interact was always important for the patients.

When I used familiar songs, I felt easier to connect to patients or could encourage more engagement from them. I also felt reassured when I was singing familiar songs with patients as I knew that they were enjoying singing or listening to the songs too.

16/6/2015: Then, I sang How Much is the Doggie at the Window. She sang together and also imitated dog barking after I imitated. We kept walking and singing. I also changed the lyric to kitten. She imitated 'miao' as well and was really engaged.

\section{6) Favourite Songs}

I used patients' favourite songs because the songs could elicit meaningful memories and good feelings experienced by patients in their earlier life. Positive memories and feelings would help to produce calming effect for patients and in turn reduce their agitated behaviours.

I communicated with patients or their family members in order to understand patients' favourite songs. There was likely to be special meaning in the patients' favourite songs, even though they might not have been able to talk about it, the songs might have helped to lessen their difficult moments or to act as a gentle distraction. Patients also communicated and interacted in more positive ways when I sang their favourite songs. The songs seemed to enable me to further support their needs as well as to extend our musical relationships. 
29/7/2015: I also invited him to sing You Are My Sunshine. He said: "We both like the song, don't we?" and "Okay!" when I asked him to sing one more time together.

7) Following the Patient

I decided to work with patients by following and walking together with them when they were wandering. I think it was important to work differently with patients who wandered so that I could build a connection with them by continually observing their facial expressions, their responses, their behaviours, their body languages, and their ways of interaction while they wandered around. Through this method, I felt like I could know them in deeper level and could properly support their needs. So, the therapeutic relationship was possible.

It seemed that close interaction with patients who wandered around was important so that they were able to receive human interaction because they almost always wandered alone. When regular meaningful interaction and meaningful relationship with people took place in their lives, patients seemed to be able to react or to respond back, interacting with their limited capability (eye contact, brief verbal, smile, gesture, body language). These minimal interactions were important elements in patients' lives. They could feel that they were connected to and were part of the people around. They could express themselves in their own different ways. Patients might feel safe, included, or have a sense of belonging during the sessions. They might also appear less anxious or less agitated. Therefore, it could help to reduce their wandering.

When I first started to work with patients who always wandered, I felt weird walking alongside them. I was afraid of what other staff would think of me singing and walking around following a patient. Some staff told me early on that music would not be effective for certain patients because they always walked. However, I later realised that it was actually important for me to be able to understand the patients in order to help them. I could only meet them on the same level by following and interacting with them. After that, I learned how music therapy would be helpful for the patients. The results were rewarding.

29/7/2015: She walked slightly fast at first, but when I hummed and followed her, she walked less fast and then stopped, and looked at me. She knew I was singing. She kept walking, I kept followed and sang to her. Then, she stopped, looked at me and smiled briefly.

8) Identity 
I emphasised the identity of patients whom were from Maori culture by relating Maori songs in a purposeful way during sessions. They might feel valued of their own ethnic culture when I asked them to sing me some Maori songs, when I asked them if they wanted to sing a song together or if they liked to listen to some songs.

By reminding them of their identity by talking about and singing Maori songs, they might feel a sense of self with their own special identity. They might also reminisce about their past. Some Maori songs seemed meaningful for them, so they showed more positive responses. When their identity was acknowledged in a musical way during a session, they might feel connected and appreciated. These feelings were important in their current life. I felt that patients often expressed themselves musically, verbally, and through facial expression or physical interaction when I invited or requested them to sing Maori songs. These responses helped to lessen their social isolation. Patients would also show less agitated behaviours.

10/6/2015: I asked if he wants to listen to some Maori songs. I chose to sing Te Aroha and introduced that this is about love...He grabbed my left hand and then kissed on it after I sang Te Aroha and asked if he likes the song. He released my hand after I asked if he wants to continue listen to songs.

9) Imitation and Matching Patients' Sound Making

I imitated and matched patients' sound making so that I could interact with them in a musical way. Patients might have limited verbal capability so it was useful to also use sound or voice to respond to them. It could also produce an effect that I was together with them in their way of expression and that we were communicating or singing together. It could support their way of expression.

I imitated and matched patients' brief sounds, voices or whistling during sessions. I allowed some time space and waited for any of their responses. It felt like a communication. I also encouraged them to respond more as I think they were able to interact using voices or sounds. I also sang songs that were similar to patients' sound making as if we were sharing the same songs. Through imitation and matching, patients might notice that their expressions and responses were being heard and acknowledged. Further engagement or interaction might occur. Patients might then feel less anxious. 
Besides, I found out that by imitating and matching the rhythms patients made would distract them from their agitated behaviours. Patients would stop what they were doing when they realised the same rhythms were being made. It often reduced patients' repetitive agitated behaviour.

14/7/2015: When passed by residents' room, he turned the door knob repetitively. I imitated the rhythm by strumming on guitar, then, he stopped, and continued walking.

10) Improvisation

I sang improvised songs during sessions as a creative music interaction. There were times when I needed to come out with simple melodies and lyrics spontaneously during sessions to match patients' feelings and to help in reducing agitation. Simple and repetitive improvised songs were sometimes engaging for them to sing along too. When patients were enjoying the improvisation, they might have better mood hence, showed less agitated behaviours.

Musical improvisation or musical exchange with patients also occurred when we were playing different musical instruments together. Although the improvisation time was short, patients seemed to naturally play instruments without any verbal prompt. Besides, it was noted that patients also directed improvisation through singing. Patients seemed to be able to express well during music.

When words of songs were improvised into simple syllabus such as 'la la la' and 'du du du' or just songs humming, calming effects could be achieved. Melodies with lesser words seemed to provide soothing feelings for patients. In addition, patients could sing along to songs with just using simple syllables without knowing the words. They could enjoy singing in such simple and improvised way.

When patients were complaining or expressing verbal anger, I often played simple improvisation on guitar softly to 'contain' the atmosphere while listened to them. It was very useful in providing calming background effects for the patients without invading or judging their verbal expression.

20/4/2015: I asked her how is she today. She said she is not good. She said she has legs sore and stomach sore. I expressed in sympathy. I then sang an improvised song “___ 's got legs sore, 's got stomach sore, 's in a lot of pain. I hope you'll be fine, I hope you'll be fine, I hope you'll be fine soon'. She smiled when listened to the song. She said 'thank you' to me. 


\section{1) Lyrics}

I changed lyrics in songs so that the lyrics were personalised, reality-oriented, and based on social norms. Residents could also take control in changing the lyrics while singing together. Improvised songs were also created with lyrics providing emotional support for patients.

During sessions, I sang simple improvised songs with lyrics related to what I thought patients were feeling and provided a positive mood change through lyrics. The songs were improvised so could be short and simple to avoid confusion. The lyrics were helpful in providing comfort for them. Lyrics from familiar songs were also adapted to remind patients what day it was, what they had with them on that day, what they were doing, and musical movement that we could do while singing together. Familiar melodic and harmonic frameworks were used because patients knew the melodies well and were able to follow the changed but simple and repetitive lyrics each time. I also gave opportunities to patients to suggest their ideas so they knew they were able to take control in the lyrics according to their likes.

Patients seemed to enjoy the adapted lyrics while singing songs together. They might feel that songs became interesting or became creative. When lyrics were all about them, they would feel included and gain support from it. Patients would also interact more when they felt comfortable and relax. Furthermore, patients often engaged well and understood the simple and repetitive lyrics easily so they would feel less anxious too.

10/6/2015: She tapped on the drums and sang along at times. Then, we sang She'll be Coming Around the Mountain. I changed the lyrics to " helps to close the window when she comes" as she was closing the windows when we walked. She tapped on drum in regular beat.

\section{2) Matching Tempo}

I matched with tempo of residents' music making by playing on guitar or singing to them, so that I could connect with them musically. When patients played musical instruments in faster tempo, I also matched, played or sang in the same tempo. Through the interaction, patients might feel that they were taking control of the music, it was important as it would allow them to further express themselves.

Playing and singing while matching with patients' walking pace when they wandered around was helpful too. Patients often received and realised that the sound or music was connected 
to them. They would also feel calm when slow tempo songs were matched and sung to them. When they were able to relate to or were attracted to the sound, more interaction could happen that would help to support patients' needs.

It seemed that patients who showed repetitive body movement were able to express themselves through music that was purposely matched. They seemed to be dancing, their movement prolonging as I played or sang and matched with their moving tempo. Brief verbal or eye contacts as interaction occurred. Furthermore, patients seemed to easily distract from their manipulation of objects when we were making sound together in the same tempo. They would realise the matching and stopped moving objects as a result. Therefore, it might help to lessen their agitated behaviours.

21/7/2015: walked in fast pace. I said hello to her and smiled. She said 'Yes...' I asked her if she wants to listen to some songs. She did not reply or give any eye contact. She kept on walking. I then observed her walking tempo, walked together and hummed When Irish Eyes Are Smiling.

13) Object, Musical Instrument (drum)

I used little drum to encourage participation from patients during sessions. It was helpful to use this drum because patients could easily tap on it while singing or listening to music. Patients seemed to enjoy drum playing or holding because it enabled them to easily engage into music.

It seemed like an invitation for music by just passing an instrument to a patient. When patients tapped on the drum while they sang along to songs, it showed that they were able to contribute to and enjoy music at the same time. Patients smiled more when they were doing something meaningful. Also, patients seemed to enjoy just playing on the drum too. It was a safe way to express themselves.

Moreover, patients could communicate with me by tapping on drum to indicate a Yes or No answer. Patients did not have to verbally interact with me but with musical interaction. It became a tool for communication and to respond and join in music together. In addition, we also took turns on tapping on the same drum with patients imitated back my rhythms. I felt connected to patients when we were able to communicate with each other. When communication and expression occurred in these ways, patients might feel less agitated. 
It was also noted that patients could lead tempo of songs with their drum playing. It showed that patients could take control in music without being judged. Also, patients had chance to interact with others by sharing and passing the drum.

5/5/2015: I grabbed little djembe and passed it to I demonstrated hitting on the drum and started singing Side by Side. I played on guitar and sang but would tap on drum again during singing spaces. Then, tapped on it too. I praise her for good playing together.

\section{4) Observation}

I observed patients' behaviour, facial expression, body language, and their interaction with me when I worked with them. I also learned to take time and to observe their different agitated behaviours so that I could meet their needs. It was also important to observe patients' walking pace in order to work effectively.

It seemed like patients could receive better support when I carefully observed them while worked with them. Even if some of them were not able to interact verbally, I could properly respond to their body language. Observation was necessary so patients could have more enjoyment during music and interaction. Patients might also feel comfortable and interact better when they were less anxious or less agitated.

Also, patients might be in different mood or different behaviour from sessions to sessions. So, a little observation before I approached them was helpful so that I could work with them in the same meeting point. Observation also seemed important in maintaining safety.

1/7/2015: I asked: "do you want to sing one more time together?” he replied 'Yeah', looked at me. I sang the song again while observing him, following his mood.

\section{5) Physical Interaction}

I had a lot of physical interaction with patients because it is important in human interaction. I worked with patients by holding or swinging their hands while singing to them when their verbal communication was minimal or impossible. I also interacted with patients with a 'hi5 ' after we sang songs or played drum together. It was my appreciation for their lovely engagement. Patients might enjoy such interaction and expression, which might lead to increased engagement and reduced agitation. 
When patients grabbed onto one of my hands tightly, I sang songs while swinging our hands in tempo. I think they would feel the musical interaction. It seemed important to maintain physical interaction while engaging with them so that they could feel the attachment. When there was attachment and musical interaction, patients might feel less anxious. Also, I sang fast tempo songs to match when patients grabbed and moved my hand in quick repetitive movement. They might be communicating with me or just expressing themselves. However, through their facial expressions, they seemed to realise that music was matching our physical interaction.

Also, I wanted to help patients who wandered around most of the time to take some rest. So, I would guide them to sit down after music as they were less agitated. I also gave physical cue by tapping on an empty couch with simple verbal instruction as an invitation for them to sit down, when they appeared to be enjoying music. Similarly, I would sit on couch while I sang and played to invite patients to sit down with me.

Patients who wandered seemed to enjoy when I held their hands and sang while moving my body in a slightly dancing manner. They would smile and give eye contact while standing in front of me. They seemed to enjoy the interaction. Moreover, tapping lightly on patients' shoulders and hands while singing slow songs to them seemed to provide a calming effect too. I noticed that some of the patients grabbed my hand or arm a lot during sessions, I wondered if they felt safer and had more of a sense of belonging when there was physical interaction.

29/7/2015: She talked a lot while walked. I followed her and hummed a song. Then, she looked at me, and talked with a frustrated facial expression. I tapped on her shoulder lightly and listened to her talking although it was incomprehensibly. She also reached out her hand, so, I took her hand and swinging little while humming. We then walked into a room, she put my hand into a basket and walked. I continued walked with her. When she walked near to a couch, I guided her to sit down, she sat.

16) Safety

I worked with patients who wandered around and would bump into walls, or grab at people and things as they passed. I needed to consider how I could keep everyone safe. I learned from experiences that I had to be extra careful while working with them so that patients could be prevented from being injured. 
I was also very conscious about my own safety when I worked with patients. I always observed carefully when I worked with patients so that I could prevent myself from getting hurt accidentally. I sometimes kept a safe distance and observed first when patients seemed agitated or if I felt that I need to protect myself.

30/6/2015: She grabbed on a patient's shoe, so, I quickly guided her away to avoid her being kicked or hurt accidentally. She started to talk a lot. I physically cued her to sit down on couch but she walked away and sat on a small table.

\section{7) Space}

I gave space for patients to join and sing together when I worked with them. It could help to support them in singing as expression when they knew the lyrics. By giving space, patients could easily join in and felt confident in singing too. When singing took part, patients might be distracted from agitation. It also seemed important to leave space in the music, just to let patients enjoy or contemplate the moment. I also gave spaces between songs so that quiet moment could provide calming effect for patients. Little verbal interaction might occur too. In addition, I gave spaces and waited patients to process or to answer any to my questions when I interacted with them. I think this was important so that patients would feel respected. Even though when verbal interaction was not possible for some patients, they could make a little sound, smile, or even brief verbal interaction with me. Also, when patients were complaining, I played on guitar softly while listened to them so that they could express themselves within the music space.

1/7/2015: I then asked him "can you sing or whistle for me?" I left space to see if he would response back. He then whistled a little. He actually whistled to songs a few times today.

18) Tempo

I used different tempo of songs to achieve different effects during sessions. I used $3 / 4$ tempo and slow tempo songs with patients to produce calming effects and to reduce anxious and/or agitation. I also used lively tempo songs to produce stimulation and for more engagement as a way of expression. Besides, patients who preferred upbeat songs could easily engage in lively songs too. Hence, they could be distracted from anxiousness.

Patients often seemed less agitated when $3 / 4$ tempo songs was sung to them. They might feel less anger or less anxious while engaged in the feeling of the tempo. The nature of $3 / 4$ tempo 
could attract patients to follow and sing together or focus on listening. So, they would feel relax or less tense afterwards. $3 / 4$ tempo songs seemed to provide calming effect for patients.

In addition, slow tempo songs could also provide soothing and calming feeling for patients. When patients were agitated, slow tempo songs allowed them to feel calm. This was demonstrated in their slower walking pace or calm facial expressions. Patients stopped their agitated behaviour and seemed enjoyed listening to the slow songs. Patients who wandered around could also be easily guided to sit down and to rest.

Also, I used slightly lively tempo songs to produce stimulation for patients. Patients interacted with eye contact, smiles, or sang along to the songs. They seemed to benefit from lively tempo songs. When patients engaged in music and interaction, they might have less agitation.

28/7/2015: I sang Let Me Call You Sweetheart, a song in 3/4 tempo, I sang it expressively and loudly. She looked at me peacefully and listened.

19) Verbal Interaction

I had a lot of verbal interaction with patients during sessions. I used short and simple phrases while interacting with them so that they could easily process my words. Patients could sense the invitation for interaction and might respond to me in their own communication ways. Some patients were able to express themselves verbally so it was important to listen and respond to them. Through verbal interactions, I built deeper relationship with patients. When verbal expression and interaction happened, patients could experience less agitation. It seemed that patients would engage more in singing or music when we had regular interaction with each other. I asked them to suggest a song to sing together, I thanked them for singing and playing music together, I gave compliments for their lovely engagement, and I looked for their feedback by asking whether or not they enjoyed music together. I also built connections with patients when we engaged in communication about music, dance, or talked about my guitar. Communication could lessen their agitation or act as a distraction. Patients could also maintain their social skills which was important in their lives.

Even if some patients talked incomprehensibly, I listened and repeated few words back to them as a response. I think it was important to support their communication and interaction. We also interacted through eye contact and gestures. Even when patients could not respond to me verbally, they would smile at me. 
1/7/2015: I asked him to sing me some songs, and said that he can sing some Maori songs. He seemed thinking and then talked something. I did not understand. But, I repeated a few words that I could get, he then replied: "Yeah".

20) Voice Only

I sometimes used voice only without accompaniment when I worked with patients. I realised that singing slow and calm songs with voice could provide calming effects for patients. Using voice only during sessions could reduce extra sounds that might confuse or agitate certain patients. Some patients appeared to react better to a calm voice. They seemed to relax and listened attentively to the singing. Therefore, it could reduce their agitation.

When I met patients who were anxious and/or agitated, I could approach them, greet them, and sing their familiar songs or favourite songs to provide soothing feeling. It was easy and useful when I did not have any other musical instruments around. Voice is a basic but important instrument. When patients were less agitated, they could interact with me musically too.

1/7/2015: I said 'hello' to him, he replied: "Hello!" I asked: "Do you want to sing some songs together?" "Yeah" "I will bring my guitar and I will play and sing ok?” "No!" "Oh ok. I will use my voice, I will sing only". "How about if I sing you a song. Somewhere over the rainbow? It is a slow and ballad song". seemed to be listening, his eye lids moved, walked slowly, stood, closed eye for seconds.

21) Volume

I sang songs in considerably loud or moderate volume when I worked with patients. With a good volume, patients could hear the music clearly as they might have slight hearing loss. When I sang songs gradually loudly, patients could also sang along confidently. Singing in loud volume seemed to provide full expression in music for some patients.

I also sang familiar songs loudly to match with patients who were agitated or talked loudly and incomprehensibly. Music seemed important in their lives so they would be distracted with the singing and appeared listening. When patients were engaged in music, they would show less agitation.

30/6/2015: I sang Loch Lomond loudly and slowly. I also tapped on her hand lightly. She seemed calm and listened, then, she felt asleep while I continued singing. 


\subsection{Case Vignette}

Jackson was a 75-year-old man who had Alzheimer's disease. He seemed have limited verbal communication, and wandered around most of the time. His agitated behaviours included pacing and aimless wandering, grabbing onto people or things inappropriately, scratching, trying to get to a different place, handling things inappropriately, and performing repetitious mannerisms. It was noted that he had verbal and physical aggressions. According to staff, he was very agitated during bath times. He would hit caregivers who were giving care to him.

One morning, I brought my guitar with me as usual, and looked around the unit. I saw Jackson standing near a wall. I approached him, looked at him and said 'hello Jackson'. He replied: "hello!" He looked at my guitar and said something unintelligible. I remembered that during past sessions, he grabbed my guitar firmly and seemed wanted to break it into two. So, I assumed that he might not like the guitar. However, he later proceeded with little whistling. I knew he sometimes whistled but I was quite surprised that he initiated musical interaction. I praised him for good whistling, then imitated back using vocal sound. He then started to walk. So, I followed and walked with him. I asked if I could play guitar and sing to him. He looked at me, said: "yeah". When he was standing in the hallway, I strummed on guitar and sang a song Puff the Magic Dragon. I was not sure if he would feel familiar to the song, but other patients around his age seemed to know it well. I wonder if he would like it. I played and sang in a slightly lively tempo to stimulate Jackson. When I was singing the song, he looked at me and seemed to be listening to it attentively.

He talked about something again. I tried to communicate with him but it seemed a bit difficult as I could not understand. I asked him if we should sing one more time together. $\mathrm{He}$ smiled at me and said: "yeah" so, I repeated the song singing with him. Later, he grabbed onto my hand firmly, and started to walk again. I let him hold onto my hand and kept following him as I think the physical interaction was important to him. Then, I asked him if he could sing a Maori song for me. He talked about something but again I could not understand. I then mentioned the song Pokarekare Ana, and started singing using my voice only as he was holding my hand. Then, he moved his and my hand in repetitive actions. I 
sang matching to the tempo. I did not know what he was feeling or thinking at that time. As he was holding my hand and moving it repetitively, I sang the song matching with his moving tempo so that I could communicate with him musically.

Then, we arrived in the lounge. I asked him whether he wanted to sit down. He again replied: "yeah", but then walked away while still holding my hand. After a while, he seemed to be talking to me or socialising to me. It was demonstrated by his eye contact, gestures, and few verbal phrases, but without discernible meanings or clear words. I could only look at him and listen while giving little responses. After that, I asked him "Do you want to listen to other songs?" He suddenly moved his hand again in fast rhythm repetitively. As he was holding on my hand, it was being moved repetitively in fast tempo as well. I did not know what he was trying to do but I quickly sang a lively song I've been working on the Railroad to match with his actions. I wonder if his repetitive behaviour would be lessened when he heard the popular and familiar music. I sang it loudly and with energy.

When I sang the chorus section, Jackson whistled. He seemed engaged in the moment. I was surprised. So, I repeated the song. He joined in again during the chorus section with his whistling. It seemed like he was connecting to the song, and to me, as we sang together. He moved his hand repetitively and whistled at the same time. After I ended the song, he slowly stopped the action. He looked at me and smiled. He seemed to have enjoyed our interaction. After that, he continued walking around again. 


\section{Discussion}

Through learning from my own experience when working with patients with dementia who were anxious and/or agitated and through readings from different articles and books about music therapy work with patients who have dementia, about person-centred dementia care, and about agitation, I believed that the knowledge had guided my work as a student music therapist. In this study, I searched for the answers to my research question using secondary analysis of data and thematic analysis. As a result, I found 21 techniques and strategies of how I worked with patients with dementia who were anxious and/or agitated. The 21 techniques and strategies were:

(1)Choice; (2)Culture of race (used Maori songs); (3)Direct Engagement; (4)Exploration; (5)Familiar Song; (6)Favourite Songs; (7)Following the Patient; (8)Identity; (9)Imitation and Matching Patients' Sound Making; (10)Improvisation; (11)Lyrics; (12)Matching Tempo; (13)Object-Musical Instrument (drum); (14)Observation; (15)Physical Interaction; (16)Safety; (17)Space; (18)Tempo; (19)Verbal Interaction; (20)Voice Only; and (21)Volume.

After I understood about different types of agitated behaviours and the explanation of agitated behaviours as "unmet needs or confusion" (Cohen-Mansfield, 1996, p.234) which patients with dementia needed to find a way to express it (Kitwood, 1997), I felt that I had more understanding of the patients when I worked with them. I also realised the importance of music therapy to support them as it could help them to have a safe verbal or nonverbal expression, to maintain or increase socialisation, to interact, or to reduce problem behaviours as the patients seemed to suffer a lot from the progressive disorder (Craig, 2014; Gold, 2014).

I learned about the importance of maintaining a positive interaction with patients to maintain their wellbeing and the five basic needs that they had (Kitwood, 1997). Through music therapy, I think patients could indirectly achieve these needs too. For instance, with the strategies and techniques that I used, singing familiar songs and calming songs with patients seemed provided a sense of comfort for them especially in alleviating their anxiety or agitation. Secondly, when I was interacting with them or engaging with them through musical interactions, they might feel the closeness or bonding as well as a feeling of attachment. Thirdly, playing musical instruments, singing together or being with patients by following them seemed to give them meaningful occupation. Fourthly, when I imitated and 
matched patients during music making or interacting with them during musical interactions, they seemed to feel included. Lastly, patients' identity could also be emphasised through learning about their past, working on their identity through some life-experience related music, or verbally interacting with them to understand about their past. So, it seemed that music therapy could support the five needs.

Also, I used other strategies and techniques such as appropriate tempo of songs when I interacted with patients so that the songs could help them to lessen their agitation or to have a positive mood change. Calming songs or other slow tempo songs were used in the sessions (Tabloski, McKinnon-Hwe \& Remington, 1995). Familiar songs and favourite songs or individualised songs were also used to help patients to reduce anxiety, agitation or to provide soothing feeling (Cox, Nowak \& Buettner, 2011; Lin, Chu, Yang, Chen, Chen, Chang, Hsieh, and Chou, 2011; Ueda, Suzukamo, Sato, \& Izumi, 2013).

However, I could not include description of my group work with patients here because as a student music therapist, I felt that it was a bit difficult to do group music therapy with patients who were agitated. It might influence the wellbeing of other patients who were in the group. But, I had experience of patients who could maintain eye contact when they happened to be attracted to the music group by sitting down together. When a patient followed and walked with another patient who always wandered, I included both of them in the meaningful music together and little interaction between them occurred too.

Also, I did not manage to use passive music listening with patients although I did make a few attempts. I wonder what effects could be achieved if I had more time for it. Some patients who were from Maori culture spoke in English only. But, after communication with family members, I continued using some popular Maori songs with them as I think the songs would help. I wondered if it was meaningful for the patients. There were also sessions which I worked on patients' identity such as being a mother, a band musician, and a former choir member. But, I could not include them here as they were not related to my research question, i.e. these patients did not often show anxious or agitated behaviours. Some of the studies which investigated the effects of music listening on anxiety and agitated behaviours on 
people with dementia did not employ qualified music therapists. I wonder if better results would have been achieved with music therapists conducting the music interventions (Craig, 2014).

Furthermore, as influenced by Kitwood and Cohen-Mansfield, I think it is very important to consider about empathy, person-centred, and patients' unmet needs when working with them rather than to only focus on their anxious or agitation. During my music therapy work, I worked on the interaction between patients and me, and tried to maintain meaningful human interaction and socialisation unless there were other more obvious needs to address such as complaining, crying, or verbal anger. I think when patients were engaging with me or interacting with me within the therapeutic relationship, they seemed more willing to communicate or to relate to me in their own ways. They could have less anxious and/or agitated too, which would affect other patients around positively. Hence, I also came out with few other music therapy related strategies and techniques when I worked with patients who were anxious and/or agitated such as: Choice, Exploration, Improvisation, Lyrics, Matching Tempo, Observation, Safety, Space, Voice Only, and Volume.

I believe that music therapy is beneficial for patients as it seems to have the quality of empathy and is person-centred too. Music therapy's focus is about the person and music is the tool to utilise during sessions. When patients seemed very agitated in various ways, if they responded with little interaction or engagement during sessions, it could probably mean that they would have their needs being met, or their psychosocial needs being met. If that happened, they might experience lesser agitation (Ridder, Stige, Qvale, \& Gold, 2013).

\subsection{Limitation}

1) I only worked with a small amount of patients who were anxious and/or agitated. So, my strategies and techniques might be different from other researchers' if larger number of patients were involved.

2) Some patients had more than one medical conditions. For example, dementia and bipolar disorder. Findings might be different if only patients who had dementia were included. 


\subsection{Implication for future Music Therapy research}

1) I did not include family members in sessions when I worked with patients. Future research about music therapy with patients with dementia who were anxious and/or agitated together with their family members would be helpful. It would also be interesting for a more experienced music therapist to investigate whether group work is effective in reducing anxiety or agitation. In addition, more work could be done to find out whether passive listening programmes, facilitated by a music therapist, might also result in a reduction of anxiety and/or agitation. 


\section{Conclusion}

My study found 21 strategies and techniques of how I worked with patients with dementia who were anxious and/or agitated. These strategies and techniques were influenced by different articles, books, or work experience that I have learned from. They were:

(1)Choice; (2)Culture of race (used Maori songs); (3)Direct Engagement; (4)Exploration; (5)Familiar Song; (6)Favourite Songs; (7)Following the Patient; (8)Identity; (9)Imitation and Matching Patients' Sound Making; (10)Improvisation; (11)Lyrics; (12)Matching Tempo;

(13)Object-Musical Instrument (drum); (14)Observation; (15)Physical Interaction;

(16)Safety; (17)Space; (18)Tempo; (19)Verbal Interaction; (20)Voice Only; and (21)Volume.

Cohen-Mansfield's description of different agitated behaviours and her definition and explanation for agitation helped me to understand about agitation in elderly people.

Kitwood's definition on personhood and his view on it, together with his emphasise on person-centred care when working with elderly people who have dementia had enriched and supported my work with patients. In relation to music therapy, I worked with different music methods to support patients who were anxious and/or agitated as well as maintaining or increasing their interaction, socialisation, and wellbeing which are all important to them. My music therapy work has been influenced by the knowledge from Cohen-Mansfield, Kitwood, and music therapy itself. Lastly, I believe that music therapy can support patients with dementia who are anxious and/or agitated. 


\section{References}

Aldridge, D., \& Aldridge, G. (1992). Two Epistemologies: Music therapy and medicine in the treatment of dementia. The Arts in Psychotherapy, 19, 243-255.

Blackburn, R., \& Bradshaw, T. (2014). Music therapy for service users with dementia: a critical review of the literature. Journal of Psychiatric and Mental Health Nursing, $21,879-888$.

Braun, V., \& Clarke, V. (2006). Using thematic analysis in psychology. Qualitative Research in Psychology, 3, 77-101.

Chang, Huang, Lin, \& Lin (2010). The effect of a music programme during lunchtime on the problem behavior of the older residents with dementia at an institution in Taiwan. Journal of Clinical Nursing, 19, 939-948.

Clare, M. (2014). Soothing sounds: reducing agitation with music therapy. Nursing \& Residential Care, 16(4), 217-221.

Cohen-Mansfield, J. (1991). Instruction manual for the Cohen-Mansfield Agitation Inventory (CMAI). USA: The Research Institute of the Hebrew Home of Greater Washington.

Cohen-Mansfield, J. (1996). Behavioral and mood evaluations: Assessment of agitation. International Psychogeriatrics, 8(2), 233-245.

Cohen Mansfield, J. (2009). Agitated behaviour in persons with dementia: The relationship between type of behaviour, its frequency, and its disruptiveness. Journal of Psychiatric Research, 43, 64-69.

Cooke, Moyle, Shum, Harrison, \& Murfield (2010). A randomized controlled trial exploring the effect of music on agitated behaviors and anxiety in older people with dementia. Aging \& Mental Health, 14(8), 905-916.

Cox, E., Nowak, M., \& Buettner, P. (2011). Managing agitated behavior in people with Alzheimer's disease: the role of live music. British Journal of Occupational Therapy, 74(11), 517-524. 
Craig, J. (2014). Music therapy to reduce agitation in dementia. Nursing times, 110(32/33), 12-15.

Creswell, J. W. (2007). Qualitative inquiry research design: Choosing among five approaches. California, USA: Sage Publications, Inc.

Dassa, A. \& Amir, D. (2014). The role of singing familiar songs in encouraging conversation among people with middle to late stage Alzheimer's disease. Journal of Music Therapy, 51(2), 131-153.

Fitzgerald-Cloutier, M., L. (1993). The use of music therapy to decrease wandering: an alternative to restraints. Music Therapy Perspectives, 11, 32-36.

Gerdner, L. A. (2000). Effects of individualised versus classical "relaxation" music on the frequency of agitation in elderly persons with Alzheimer's disease and related disorders. International Psychogeriatrics, 12(1), 49-65.

Gerdner, L. A., \& Swanson, E. A. (1993). Effects of individualised music on confused and agitated elderly patients. Archives of Psychiatric Nursing, 7(5), 284-291.

Gold, K. (2014). But does it do any good? Measuring the impact of music therapy on people with advanced dementia: (Innovative practice). Dementia, 13(2), 258-264. doi: $10.1177 / 1471301213494512$

Heaton, J. (2004). Reworking qualitative data. London: Sage Publications Ltd.

Harrison, Cooke, Moyle, Shum, \& Murfield (2010). Development of a music intervention protocol and its effect on participant engagement: Experiences from a randomised controlled trial with older people with dementia. Arts \& Health, 2(2), 125-139.

Kitwood, T. (1997). Dementia reconsidered: The person comes first. Philadelphia, USA: Open University Press.

Lin, Y., Chu, H., Yang, C., Chen, C., Chen, S., Chang, H., ... \& Chou, K. (2011).

Effectiveness of group music intervention against agitated behavior in elderly persons with dementia. International Journal of Geriatric Psychiatry, 26, 670-678.

Ledger, A. J., \& Baker, F. A. (2007). An investigation of long-term effects of group music therapy on agitation levels of people with Alzheimer's Disease. Aging and Mental Health, 11(3), 330-338. 
McDermott, O., Orrell, M., \& Ridder, H. M. (2014). The importance of music for people with dementia: The perspective of people with dementia, family carers, staff and music therapists. Aging \& Mental Health, 18(6), 706-716. doi: 10.1080/ 13607863.2013 .875124

Ridder, H. M. O., Stige, B., Qvale, L. G., \& Gold, C. (2013). Individual music therapy for agitation in dementia: an exploratory randomised controlled trial. Aging and Mental Health, 17(6), 667-678.

Schwandt, T. A. (2001). Dictionary of qualitative inquiry. London, UK: Sage Publications, Inc.

Smith, E. (2008). Using Secondary Data in Educational and Social Research. Berkshire, England: Open University Press.

Sole, C., Mercadal-Brotons, M., Galati, A., \& Castro, M. D. (2014). Effects of group music therapy on quality of life, affect, and participation in people with varying levels of dementia. Journal of Music Therapy, 51(1), 103-125.

Sung, H., Lee, W., Li, T., \& Watson, R. (2012). A group music intervention using percussion instruments with familiar music to reduce anxiety and agitation of institutionalized older adults with dementia. International Journal of Geriatric Psychiatry, 27, 621627.

Tabloski, P. A., McKinnon-Howe, L., Remington, R. (1995). Effects of calming music on the level of agitation in cognitively impaired nursing home residents. The American Journal of Alzheimer's Care and Related Disorders \& Research, January/February, $10-15$.

Tan, L. L., Wong, H. B., \& Allen, H. (2005). The impact of neuropsychiatric symptoms of dementia on distress in family and professional caregivers in Singapore. International Psychogeriatric, 17(2), 253-263. doi: 10.1017/S1041610205001523

Thomas, D. R. (2006). A general inductive approach for analyzing qualitative evaluation data. American Journal of Evaluation, 27(2), 237-246.

Ueda, T., Suzukamo, Y., Sato, M., Izumi, S. (2013). Effects of music therapy on behavioral and psychological symptoms of dementia: A systematic review and meta-analysis. Ageing Research Reviews, 12, 628-641. 
Valderas, J. M., Starfield, B., Sibbald, B., Salisbury, C., \& Roland, M. (2009). Defining comorbidity: Implications for understanding health and health services. Annals of Family Medicine., 7(4), 357-363.

Vink, A. C., Zuidersma, M., Boersma, F., Jonge, P., Zuidema, S. U., Slaets, J. P. J. (2013). The effect of music therapy compared with general recreational activities in reducing agitation in people with dementia: a randomised controlled trial. International Journal of Geriatric Psychiatry, 28, 1031-1038.

Wall, M., \& Duffy, A. (2010). The effects of music therapy for older people with dementia. British Journal of Nursing 19(2), 108-113.

World Health Organization (2012). Dementia. Retrieved from http://www.who.int/mediacentre/factsheets/fs362/en/ 


\section{Appendices}

Appendix 1

\section{How did a Music Therapy Student Work with Patients with Dementia Who Were Anxious and/or Agitated?}

INFORMATION SHEET for client's family member

Dear Family Member

My name is and I am the music therapy student working with at I am currently on placement as a second year music therapy student. This is my second and final year as part of a Master of Music Therapy degree at New Zealand School of Music, Victoria Wellington.

I am required to research about music therapy as part of my training. For my research topic I have chosen to explore how music therapy can support people who have agitation associated with dementia. My research project will focus on the strategies and techniques that I used while working with patients with dementia who have agitation and/or anxiousness. As a result of this project, I hope to learn from my work as a student music therapist, to improve my own practice in the future, and potentially to provide useful information for other music therapists or music therapy students who also work in dementia units or aged care settings in New Zealand.

My research process will involve looking back at my practice notes, and journal reflections about music therapy work with residents to answer my research question. I will be writing a document about my research, and there will be a section called case vignette which will illustrate any musical experiences or meaningful interactions that are relevant to my research topic.

I would like to ask you to give written permission for some materials relating to recorded in my notes and reflections to be included in this research. This information contains specific musical and personal experiences with during music therapy sessions. I will not use names or other information that can potentially identify him/her in any publication or presentation of this research. All the records and consent forms for this research will be stored in a locked cupboard and kept for ten years at New Zealand School of Music. However, there is a possibility of being recognised as there are only a few specialist hospitals in Aotearoa New Zealand. I will make every attempt to protect 's privacy and confidentiality.

I will provide a summary of the results of the study to you if you wish to see the findings of this project, but please note that this study may not be ready for publication until early 2016 . I will be happy to discuss with you about this study during and/or after the study. 
The proposal for this study has been reviewed and approved by the New Zealand School of Music Postgraduate Committee. Victoria University Human Ethics Committee has given generic approval for me to carry out this project and they have considered it to be low risk.

Please feel free to discuss with my clinical liaison, or me about my research and/or giving permission to use the music therapy materials in the research. If you feel you have obtained sufficient information about this research and happy to give permission, please sign the enclosed consent form. There will be no changes to the ongoing music therapy even if you decide not to give your permission. You can contact my research supervisor if you have any concerns or questions relating to this research.

This project has been reviewed and approved by the New Zealand School of Music Postgraduate committee. The Victoria University of Wellington Human Ethics Committee have given generic approval for music therapy students to conduct studies of this type, reference The music therapy projects have been judged to be low risk and, consequently, are not separately reviewed by any Human Ethics Committees. The supervisor named below is responsible for the ethical conduct of this research. If you have any concerns about the conduct of this research, please contact the supervisor or, if you wish to raise an issue with someone other than the student or supervisor, please contact Victoria University of Wellington.

Please take time to consider this request, and feel free to contact me or my research supervisor if you have any questions about the project.

If you are willing for me to use your family's data in my research, please complete the attached consent form.

Music Therapy Student:

Name:

Mobile:

Email:

Research Supervisor:

Name:

School:

Email:

Thank You 


\section{How did a Music Therapy Student Work with Patients with Dementia Who Were Anxious and/or Agitated?}

Parent, Caregiver or Family Member's Consent Forms

- I have read the information sheet and have obtained sufficient information about the study.

- I understand that my family member's name will be changed and that the location and name of the setting will not be identified.

- I also understand that the research data will be kept in a locked cupboard at the New Zealand School of Music for a period of 10 years.

- I acknowledge that the study will be published in the library at Victoria University and may be presented in a conference or published paper.

- I understand that I can contact the student music therapist and her research supervisor if I have any concerns or questions relating to the research.

- I also understand that I can contact the Victoria University of Wellington Human Ethics Convenor if I have any other concerns about this research.

I therefore give consent for materials recorded in music therapy student's clinical notes and reflective journal that are related to my family member's music therapy to be used in a case vignette to illustrate the findings of the research.

Signature:

Date:

(Family Member)

Full name printed: 


\section{Appendix 3:}

First, I read my clinical notes and paid attention on data that showed what I had done during my interaction with patients. I collated the data into 'What I Did' column and also wrote down each agitated behaviours that were shown by the patients. Below is one of the example:

\begin{tabular}{|l|l|}
\hline Agitation & What I Did \\
\hline $\begin{array}{l}\text { Pacing and aimless } \\
\text { wandering, performing } \\
\text { repetitious mannerisms. } \\
(21 / 7 / 15)\end{array}$ & $\begin{array}{l}\text { Handed her a drum, asked her if she wants to take the drum, } \\
\text { repeated with her counting 1,2,3,4,5 while strummming on } \\
\text { guitar, following her walking and kept strumming, sang Ten } \\
\text { Guitars chorus section, asked her what songs she wants to } \\
\text { sing next, sang You Are My Sunshine-sun shines bright } \\
\text { today, sang 'She'll be coming on the Mountain when She } \\
\text { Comes'-lyrics changed to 'She'll be tapping on drum when } \\
\text { she comes' when she tapped on drum, asked her if she can } \\
\text { pass the drum to resident sitting next to her, asked her to } \\
\text { sing us a Maori song, suggested and started singing } \\
\text { Pakarekare Ana and strummed on guitar, suggested and } \\
\text { sang Jamaica Farewell to end the session, thanked her and } \\
\text { the resident sitting next to her for singing together and } \\
\text { playing drum. }\end{array}$ \\
\hline
\end{tabular}

Then, based on the information in 'What I Did' column, I produced different codes.

\begin{tabular}{|c|c|c|c|}
\hline Agitation & What I Did & Code & \\
\hline $\begin{array}{l}\text { Pacing and } \\
\text { aimless } \\
\text { wandering, } \\
\text { performing } \\
\text { repetitious } \\
\text { mannerisms. } \\
(21 / 7 / 15)\end{array}$ & $\begin{array}{l}\text { asked her to sing us a Maori } \\
\text { song, suggested and started } \\
\text { singing Pakarekare Ana and } \\
\text { strummed on guitar }\end{array}$ & $\begin{array}{l}\text { Culture of race (used } \\
\text { Maori song) }\end{array}$ & $\begin{array}{l}\text { I used the song to } \\
\text { engage her back into } \\
\text { our session. }\end{array}$ \\
\hline $\begin{array}{l}\text { Pacing and } \\
\text { aimless } \\
\text { wandering, } \\
\text { performing } \\
\text { repetitious } \\
\text { mannerisms. } \\
(21 / 7 / 15)\end{array}$ & $\begin{array}{l}\text { sang Ten Guitars chorus } \\
\text { section, asked her what songs } \\
\text { she wants to sing next, sang } \\
\text { You Are My Sunshine-sun } \\
\text { shines bright today, sang } \\
\text { 'She'll be coming on the } \\
\text { Mountain when She Comes' - } \\
\text { lyrics changed to 'She'll be } \\
\text { tapping on drum when she } \\
\text { comes' when she tapped on } \\
\text { drum, suggested and sang }\end{array}$ & Familiar Songs & $\begin{array}{l}\text { I used familiar songs } \\
\text { to engage with her, } \\
\text { to match the bright } \\
\text { sunshines day, and } \\
\text { during one song it } \\
\text { was easy to change } \\
\text { lyrics. }\end{array}$ \\
\hline
\end{tabular}




\begin{tabular}{|c|c|c|c|}
\hline & $\begin{array}{l}\text { Jamaica Farewell to end the } \\
\text { session. }\end{array}$ & & \\
\hline $\begin{array}{l}\text { Pacing and } \\
\text { aimless } \\
\text { wandering, } \\
\text { performing } \\
\text { repetitious } \\
\text { mannerisms. } \\
(21 / 7 / 15)\end{array}$ & $\begin{array}{l}\text { Handed her a drum, asked her } \\
\text { if she wants to take the drum, } \\
\text { repeated with her counting } \\
1,2,3,4,5 \text { while strumming on } \\
\text { guitar, followed her when she } \\
\text { walked and kept strumming }\end{array}$ & Following Patient & $\begin{array}{l}\text { I followed her to } \\
\text { engage with her. }\end{array}$ \\
\hline $\begin{array}{l}\text { Pacing and } \\
\text { aimless } \\
\text { wandering, } \\
\text { performing } \\
\text { repetitious } \\
\text { mannerisms. } \\
(21 / 7 / 15)\end{array}$ & $\begin{array}{l}\text { asked her to sing us a Maori } \\
\text { song, suggested and started } \\
\text { singing Pakarekare Ana and } \\
\text { strummed on guitar }\end{array}$ & Identity & $\begin{array}{l}\text { I valued her own } \\
\text { ethnic culture by } \\
\text { asking her to sing us } \\
\text { a Maori song. }\end{array}$ \\
\hline $\begin{array}{l}\text { Pacing and } \\
\text { aimless } \\
\text { wandering, } \\
\text { performing } \\
\text { repetitious } \\
\text { mannerisms. } \\
(21 / 7 / 15)\end{array}$ & $\begin{array}{l}\text { repeated with her counting } \\
1,2,3,4,5 \text { while strummming } \\
\text { on guitar, sang 'She'll be } \\
\text { tapping on drum when she } \\
\text { comes' when she tapped on } \\
\text { drum }\end{array}$ & $\begin{array}{l}\text { Imitated and } \\
\text { matching patient's } \\
\text { sound making }\end{array}$ & $\begin{array}{l}\text { I imitated her } \\
\text { counting } 1-5 \text { while } \\
\text { strummed on my } \\
\text { guitar. }\end{array}$ \\
\hline $\begin{array}{l}\text { Pacing and } \\
\text { aimless } \\
\text { wandering, } \\
\text { performing } \\
\text { repetitious } \\
\text { mannerisms. } \\
(21 / 7 / 15)\end{array}$ & $\begin{array}{l}\text { sang You Are My Sunshine- } \\
\text { sun shines bright today, sang } \\
\text { 'She'll be tapping on drum } \\
\text { when she comes' when she } \\
\text { tapped on drum, suggested } \\
\text { and sang Jamaica Farewell to } \\
\text { end the session }\end{array}$ & $\begin{array}{l}\text { Lyrics } \\
\text { (personalised...reality } \\
\text { oriented) }\end{array}$ & $\begin{array}{l}\text { I changed the lyrics } \\
\text { to something that } \\
\text { she was doing, and } \\
\text { sang a song to match } \\
\text { weather of the day. }\end{array}$ \\
\hline $\begin{array}{l}\text { Pacing and } \\
\text { aimless } \\
\text { wandering, } \\
\text { performing } \\
\text { repetitious } \\
\text { mannerisms. } \\
(21 / 7 / 15)\end{array}$ & $\begin{array}{l}\text { Handed her a drum, asked her } \\
\text { if she wants to take the drum, } \\
\text { sang 'She'll be tapping on } \\
\text { drum when she comes' when } \\
\text { she tapped on drum, asked her } \\
\text { if she can pass the drum to } \\
\text { resident sitting next to her, } \\
\text { thanked her and the resident } \\
\text { sitting next to her for singing } \\
\text { together and playing drum. }\end{array}$ & $\begin{array}{l}\text { Object, Musical } \\
\text { Instrument (drum) }\end{array}$ & $\begin{array}{l}\text { I offered her a drum } \\
\text { so that we can have } \\
\text { musical interactions } \\
\text { through playing } \\
\text { instruments-and } \\
\text { possible interaction } \\
\text { with another } \\
\text { resident. We also } \\
\text { 'communicated' by } \\
\text { taking turns in } \\
\text { tapping on the same } \\
\text { drum. She seemed } \\
\text { 'communicated' with }\end{array}$ \\
\hline
\end{tabular}




\begin{tabular}{|l|l|l|l|}
\hline & & & $\begin{array}{l}\text { me too, by tapping } \\
\text { on drum together. }\end{array}$ \\
\hline $\begin{array}{l}\text { Pacing and } \\
\text { aimless } \\
\text { wandering, } \\
\text { performing } \\
\text { repetitious } \\
\text { mannerisms. } \\
(21 / 7 / 15)\end{array}$ & $\begin{array}{l}\text { Handed her a drum, asked her } \\
\text { if she wants to take the drum, } \\
\text { asked her what songs she } \\
\text { wants to sing next, asked her } \\
\text { if she can pass the drum to } \\
\text { resident sitting next to her, } \\
\text { asked her to sing us a Maori } \\
\text { song, suggested and started } \\
\text { singing Pakarekare Ana and } \\
\text { strummed on guitar, thanked } \\
\text { her and the resident sitting } \\
\text { next to her for singing } \\
\text { together and playing drum. }\end{array}$ & Verbal Interaction & $\begin{array}{l}\text { I asked her what } \\
\text { songs we should } \\
\text { sing next to give her } \\
\text { freedom in } \\
\text { suggesting songs to } \\
\text { sing together. I } \\
\text { thanked her for } \\
\text { singing together and } \\
\text { playing drum to } \\
\text { acknowledge her } \\
\text { engagement with me } \\
\text { in the session. }\end{array}$ \\
& & & \\
\hline
\end{tabular}

After all of the clinical notes were analysed, same codes were then grouped together. For example:

\begin{tabular}{|l|l|l|l|}
\hline Agitation & What I Did & Code & \\
\hline $\begin{array}{l}\text { Pacing and } \\
\text { aimless } \\
\text { wandering, } \\
\text { performing } \\
\text { repetitious } \\
\text { mannerisms, } \\
\text { general } \\
\text { restlessness. } \\
(30 / 6 / 15)\end{array}$ & $\begin{array}{l}\text { left space for her to sing Doh Reh } \\
\text { Tipperary, Que Sera Sera, and } \\
\text { How Much } \text { is the Doggie at the } \\
\text { dog imitation). }\end{array}$ & Familiar Song & $\begin{array}{l}\text { I used familiar songs } \\
\text { so that she could } \\
\text { express herself } \\
\text { through singing. }\end{array}$ \\
\hline $\begin{array}{l}\text { Pacing and } \\
\text { aimless } \\
\text { wandering } \\
(1 / 7 / 15)\end{array}$ & $\begin{array}{l}\text { Singing It's a Long Way to } \\
\text { (from most of session, realised he } \\
\text { knows this song). }\end{array}$ & Familiar Song & $\begin{array}{l}\text { I used a familiar song } \\
\text { that he knew (my } \\
\text { experience from } \\
\text { previous sessions) to } \\
\text { provide a meaningful } \\
\text { moment while he } \\
\text { walked. }\end{array}$ \\
\hline $\begin{array}{l}\text { Repetitive } \\
\text { sentences or } \\
\text { questions } \\
(29 / 7 / 15)\end{array}$ & $\begin{array}{l}\text { Greeted him, sang Camptown } \\
\text { Races to him- gave space for him } \\
\text { to sing 'Doo Dah Doo Dah' and } \\
\text { 'Oh Dee Doo Dah Day', hummed } \\
\text { and sang When Irish Eyes Are }\end{array}$ & Familiar Song & $\begin{array}{l}\text { I sang familiar songs } \\
\text { to engage with him, to } \\
\text { have positive } \\
\text { interaction with him. }\end{array}$ \\
\hline
\end{tabular}




\begin{tabular}{|l|l|l|l|}
\hline & $\begin{array}{l}\text { Smiling, invited him to sing You } \\
\text { Are My Sunshine together. }\end{array}$ & & \\
\hline
\end{tabular}

Any codes that were missed earlier were added in to the same group or into another new group. Then, important features of data from each groups were then identified and explained in broader aspects as related to the research question. 